\title{
The Social Network of High and Low Self- Monitors and it's Impact on Organization's Performance
}

\author{
Fahim Shaker
}

Lecturer, School of Business Studies, Southeast University, Bangladesh

\begin{abstract}
Self-monitoring as a personality attribute is given particular attention by researchers in order to understand employee performance and productivity in the organizational context. Numerous studies focused on the impact of self-monitoring from individual employee perspective with limited focus on the impact of the organization's performance. However, to what extent employees with high versus low self- monitors contribute to the organization's performance needs to be theoretically augmented. Therefore, relying on exploratory method of research, the paper tries to address the impact of high and low selfmonitors on organization's performance. In this perspective, how self-monitoring helps employees to structure a social network within organizational setting and eventually contribute to it's success is discussed in this paper. The paper addresses the literature review of self-monitoring principles with special interest in its contribution towards organizational performance through previous research compilation within the field of sociology and organization psychology.
\end{abstract}

Keywords: Self-Monitoring, Social Network, Organization, Performance JEL Classification Code: M 12; M 14

\section{INTRODUCTION}

Historically it's observed that in any organization, some employees perform better than others. To understand the underlying motivations behind the superior performance by few individuals in organizations, the role of personality is given special attention to the research within this paradigm. The study of personality within industrial and organizational psychology mostly relies on the big five personality model (Openness to experience, Conscientiousness, Extraversion, Agreeableness and Neuroticism) and mostly ignores other personality variables such as 'self- monitoring' (Day and Schleicher, 2006). Few scholars (Gangestad \& Snyder, 1985; Snyder, 1974) described the influential role of self- monitoring in the work context. Self- monitoring as a personality variable is understood to be significantly relevant in determining "attitudes, behaviors, and outcomes that constitute the primary criterion domains in organizational settings." (Day and Schleicher, 2006: 687).

Self- monitoring is described as one of the personality variables that influences job productivity. It is suggested to be a relevant factor to understand employee performance within $t$ he organization. However, before addressing how 'self- monitoring' may help an employee to become a better performer, it is important to determine how and why this factor is relevant to assess employee's performance. Higher performance may lead to higher individual and organizational success and it's important to discuss the relevancy of self- monitoring principles within the context of individual work success (Borman \& Motowidlo, 1993; Day \& Schleicher, 2006). Hogan (1983) described three primary motives as driving factors behind the individual success within work context. These are"individual's need for (a) acceptance and approval, (b) status, power and control of resources and (c) predictability and order." (Hogan and Warrenfeltz, 2003: 77). These three motives help individuals to get along with others in the group, to progress forward in their career through higher structural position and to help them to make a proper judgment about the environment. (Day \& Schleicher, 2006). The authors (Day \& Schleicher, 2006: 688) described these three driving factors are helpful for individuals to "get along, get ahead and make sense of the world." While every individual is believed to be in the process of getting along, getting ahead and trying to make sense of the world, significant differences are observed in their efforts of doing so. (Hogan \& Holland, 2003). Those observed differences are metaphorically caused by the way individuals selfmonitor themselves. (Hogan \& Holland, 2003; Day \& Schleicher, 2006). Therefore, it's understood that the individuals differ in their self-monitoring principles and occupy different structural positions in organizations. (Mehra, Kilduff and Brass, 2001). People with these differences are either considered to be either high or low self-monitored individuals (Rosenberg et al. 2011).

Previous studies on self-monitoring principles have mostly focused on how self -monitoring principles account for different structural positions in organizations. (Kilduff et al. 2008). One of the studies was addressed towards Korean expatriate Small business owners in North America to examine how high self-monitored individuals strive for higher social acquaintances and settle for higher structural positions. The same study suggests a ripple effect on personality in social network 
where people with lower self-monitored principles settle for junior positions in the organizations and end up with limited social acquaintances (Oh and Kilduff, 2008). However, the overreaching scope of the current paper is not to examine how people settle for different structural positions due to their differentiated self-monitored principles. The current paper is rather aimed to theoretically explore the literatures and relevant concepts within self -monitoring principles to understand how these may affect an organization's overall performance. Here, the organization is described from the 'social network' context since individuals in an organization tend to maintain several associations inside and outside the boundary of their workplace. (Hansen 1999). Since organizations tend to interact with each other for various strategic purposes (Kilduff \& Tsai, 2003), there exists a need amongst employees to socially interact with each others to cultivate a range of associations and form a social network in organizations. It will be discussed in the review section of the literature in details.

\section{Objective of the Study}

Therefore, the scope of the current paper is to theoretically augment the research within self monitoring principles to understand how social network of high versus low self- monitored individuals affect an organization's performance. The current paper is aimed to serve the literal review of 'self-monitoring' principles borrowing from the classic and contemporary texts within the field of sociology, and organizational psychology. Staying aligned with the core objective of the paper; the paper is going to highlight-

- High versus low self- monitoring principles

- Organizations as a system of social network

- Structural differences in organization due to high versus low self-monitoring principles

- Social network of high versus low self- monitors and its impact on competition

- The emergence of high self- monitored individuals as leaders

- The interaction process of High and low selfmonitored individuals in organizational setting.

\section{Methodology}

The current paper follows an exploratory research method. The study mostly conducted through secondary sources of data compiled from various journals, publications and early research work within this paradigm. The required references are provided in the bibliography of the paper.

\section{SigNIFICANCE OF THE STUDY}

The current paper may have higher significance to understand the relationship between the self-monitoring attributes and the performance of an organization. This paper would try to explain how employees within different organizations in an industry can form a social network and thus contribute to the organization's performance through their self-monitoring attributes. The study may be significant from a theoretical point of view since the study is compiled with the help of ample research work and scholarly articles relating to the context of the article.

\section{Literature REVIEW}

In this particular section, literature within the selfmonitoring personality attributes (High versus low self monitors) in the context of social network is going to be discussed to exemplify its significance to organization's performance.

\section{High- Low Self- Monitoring Principles}

'Self-monitoring' is described as the process to regulate, control and maintain their behavior to impose a favorable and desirable self-image to others. (Rosenberg et al. 2011). They can be either described as high or low self-monitors in the organizational context. (Kilduff \& Tsai, 2003). High self-monitors are supposedly having high- level adjustability to different social situations and they can self-control their image. According to Mehra (et al. 2001), high self-monitors are described as high image conscious, hyper sensitive to social norms and can engage themselves in socially appropriate behaviors. Entrenched with superior judgmental capability, high self-monitors have a proper idea about what to express and what not to based on cultural suitability context. They can be described as image manipulators to impose a more desirable self-image of themselves in order to gain social acceptability. (Mehra et al. 2001). Contrary to this, low self-monitors have insignificant exposures about social cues typically due to their lower understandability level about assessing different social conditions. They tend to be self-expressive without being highly image conscious. (Rosenberg et al. 2011). Low self-monitors are less cautious than others when it comes to their selfpresentation tactics and do not intensify high selfcontrolled behavior in social networks. It can be argued that they have more authenticity in their self-presentation tactics since they prefer less self-image manipulation.

\section{Organizations as Social Network}

Network is defined as "set of nodes and set of ties that suggests stability." (Kilduff \& Tsai, 2003:87). "Social networks in organizations tend to be based on hierarchy, density, embeddedness" (Kilduff \& Tsai, 2003:87) and so on. With the development of sophisticated methods of operation, the complexity within the workforce is so apparent now a day that, it requires dynamic adaption of the individuals within the organization. Therefore, firms are not engaged only in the production; they are also engaged in strategic planning, internationalization, $\mathrm{R} \& \mathrm{D}$ and competitive strategies. There exists a need of social network in which organizations tend to interact with each other through knowledge sharing, experience and innovation (Hansen, 1999). Because of this, 
there are large numbers of individuals within organizations having a range of network associations in the form of business partners, affiliation, club membership, VIP membership to professional intuitions.

These people who tend to have a wide range of network associations are generally high performers of the organization, and their performance is enriched with the help of networks they maintain. This is in term of structural position, where some people have advantageous positions due to their affiliations. These allow them to access others who were otherwise disconnected, to address any deviation within the organization through facilitation of resource flows and knowledge sharing across the organizations. (Kilduff \& Tsai, 2003). As described by Kilduff \& Tsai (2003), they are the people with high self-monitoring power contributes to the better performance of the organizations. To understand the contributions of self-monitoring to the organization, the self- monitoring in network positions were classified under three models, in which high selfmonitored individuals are able to move to the central position, take advantage of the resources because of their position, and outperform the low self- monitored individuals. (Kilduff \& Tsai, 2003). Therefore, the high self- monitored individuals are described as key persons in the network position of the organization, since they can collaborate and compromise within themselves to resolve their conflicts. (Baron, 1989) and tend to emerge as group leaders (Zaccaro et.al. 1991). Eventually, the high selfmonitored individuals would take the central role in decision making. They are quite adjacent to the rapid changes in the organizations and more likely to response positively with the changes brought in the system.

\section{Social Network of High versus Low Self- Monitors and Impact on Competition}

In a highly competitive market, it's necessary for firms to keep pace with others through maintaining diverse set of networks within each others to explore the possibilities to outperform each other's. It's essential for a competing firm to explore industry trends, fetch confidential market information, seek and recruit industry experts from competing firms, snatch the formula of best practice and adopt dynamic strategies to sustain in the market with top result. David Harvey (1990) in his famous 'time space compression' theory, described the present era as post modernism, in which vast mobility and internationalization of capital is taking place. Therefore, firms are required to be responsive enough to speed-up or to accelerate "the turnover time of capital" (Harvey, 1990). Firms can be highly responsive by setting industry standard such as adopting a formula which can outperform the competitors. Alternatively, they can also adopt a conservative approach by just following what they had been consistently doing over the time (Desmond, 2003). Therefore, the essence of social network in highly competitive industry cannot be underestimated since it provides the threshold to the competitor's activities. However, firms with a conservative approach do not require high self-monitored individuals as their focus is not to become the market leader. Their positions in the industry can be described as rather 'static'. Therefore, individuals with lower self- monitoring personalities may not endanger the organization's performance since they don't find the necessity for maintaining an array of network in the industry.

\section{High Self-Monitors as Emarging Leaders}

According to Kenny and Zaccaro (1983), emerging individual leaders may face the needs of the group and patronize their behavior accordingly. The past research supports the fact that individuals with higher selfmonitoring capability possess the skills of leadership. From the perspective of competition, this is very crucial since leaders are responsible for setting industry standards, which other firms likely to follow. The leaders require the dynamic adoption of the workforce which consists of a wide range of units and subunits, resulting in a wider array of networks within these units starting from supply chain management to IT management and outsource management. The individuals with lower personality traits of self- monitoring may not be effective in this regard since, the positions of leaders require dynamic presence of mind within organization that faces consistent force of competition from the market. (Burt, 1992).

\section{The Interaction of High Versus Low Self- Monitored Individuals in Organizations}

One critical aspect of self- monitoring principles is the way individuals interact with others in an organizational setting. As described by Kilduff \& Tsai (2003) with the context of Goffman (1959), "the advantages that accrue to those who adopt attitudes and behaviors to the demands of social changes". (Kilduff \& Tsai, 2003:81). An interesting example is the case of healthcare institutions consisting of mental patients. Nurses in such institutions need to deal with variety of patients suffering from various mental disorders. They require adaptation of different attitudes and behaviors depending on different situational cases (Goffman, 1959). Individuals with high self- monitored personality traits are likely to hang out with wide range of characters rather than people with only one type of characteristics (Kilduff \& Tsai, 2003). They are more likely to approach the organizational problems in a more constructive way with considering wide range of alternatives. With the inclusion of social networks within organization, the high self- monitored individuals are introduced with wide range of alternatives in addressing various issues of organizational context. Therefore, the decision making process doesn't become static and critical evaluation of the problem is explored. Thus with the help of critical experience gained through different social networks, the leaders are being able to address the problems in more creative ways. 
However, if we explain the way high and low selfmonitored individuals interact with others, we may discover that, the high self- monitored individuals rather follow diplomatic approaches instead of being simple (Kilduff and Tsai, 2003). One problem of being diplomatic is that, it may fail to promote constructive resistance in the organization. High self- monitored individuals are more adaptative to the situational change and show less resistance. They may typically fail to address any shortfall in the organizations since they prefer to support more and complain less (Kilduff \& Tsai, 2003). Therefore, promoting healthy and constructive resistance addressing shortfall and deviations may not be a common practice amongst the high self- monitored individuals because of their tendency towards diplomatic approaches to address situations. Individuals with lower self- monitored personality traits may be proven much effective here, since they are usually straight-forward with their approaches, and many deviations can be addressed by hearing them. However, their voice may be hurt due to the overshadowed and charismatic presence of high self- monitored individuals. They usually grab the top positions in the organizations and tend to dominate the low self- monitored individuals through the practice of power. (Kilduff \& Tsai, 2003).

\section{CONCLUSION AND IMPLICATIONS FOR FUTURE RESEARCH}

Kilduff \& Tsai (2003), in the book 'social organization \& networks' have highlighted the importance of research in bureaucratic organizations to understand the impact of self- monitoring personality attributes towards organizational performance. With my understanding, I tried to explore the areas of competition in which selfmonitoring and networking may play a vital role and thus giving the organization an upper hand of others. However, the current body of research is not supported by empirical evidence which is a research limitation. Future research in this field may be supported by empirical evidence where the reflection of an organizational performance is explained through the phenomena of self-monitoring principles. Also, self-monitoring principles are explained in the context of a competitive market where organizations with high self- monitored individuals achieve competitive advantage. However, to what extent, the self- monitoring personality traits and networking would be significant in terms of a monopolistic market is needed to be addressed through future research.

\section{REFERENCES}

Aktar S, Islam MS and Hossen SM. 2012. Human Resource Management Practices and Firms Performance in Bangladesh: An Empirical Study on Pharmaceutical Industry Asian Business Review, 1, 121-125.

Baron, R. A. 1989. Personality and organizational conflict: Effects of the Type A behavior pattern and self-monitoring. Organizational Behavior and Human Decision Processes, 44: $297-344$
Borman, W. C., \& Motowidlo, S. J. (1993). Expanding the criterion domain to include elements of contextual performance. In N. Schmitt \& W. C. Borman (Eds.), Personnel selection in organizations (pp. 71-98). San Francisco: Jossey-Bass.

Burt, R. S. (1992). Structural holes: The social structure of competition. Cambridge, MA: Harvard University Press

Day, D. V., and Schleicher, D. J. (2006). Self-monitoring at work: A motive based perspective. Journal of Personality, 74 (3): 685-710.

Dooty EN and Islam MS. 2014. Investment Performance of Islamic Bank: An Empirical Study Asian Business Review, 4, 37-40.

Gangestad, S. W., \& Snyder, M. (1985). "To carve nature at its joints": On the existence of discrete classes in personality. Psychological Review, 92, 317-349

Goffman, Erving (1959), The presentation of self- in everyday life. New York: Anchor Books

Hansen, Morten T. (1999) 'The Search-Transfer Problem: The Role of Weak Ties in Sharing Knowledge across Organization Subunits', Administrative Science Quarterly 44: 82-111

Harvey, D. 1990. "Between Space and Time: Reflections on the Geographical Imagination." Annals of the Association of American Geographers 80:418-434.

Hogan, J., \& Holland, B. (2003). Using theory to evaluate personality and job performance relations: A socio-analytic perspective. Journal of Applied Psychology, 88, 100-112.

Hogan, R. (1983). A socio-analytic theory of personality. In M. M. Page (Ed.), 1982 Nebraska symposium on motivation (pp. 55-89). Lincoln: University of Nebraska Press.

Hogan, R., \& Warrenfeltz, R. (2003). Educating the modern manager. Academy of Management Learning and Education, 2, 74-84.

Hossain M, Abdullah AM and Farhana S. 2012. Performance Appraisal \& Promotion Practices on Private Commercial Bank in Bangladesh: A Case Study from Pubali Bank Ltd. Asian Business Review, 1, 49-55.

John Desmond (2003) Consuming Behavior, Palgrave Macmillan.

Kabir F and Islam N. 2013. Leadership Approaches and its Impact on Follower Development and Performance Asian Business Review, 3, 44-52.

Kenny, D. A., \& Zaccaro, S. J. (1983). An estimate of variance due to traits in leadership. Journal of Applied Psychology. 68, $678-685$

Kilduff, M., Crossland, C., Tsai, W., \& Krackhardt, D. 2008. Organizational network perceptions versus reality: A small world after all? Organizational Behavior and Human Decision Processes, 107: 15-28

Kilduff, Martin \& Tsai Wenpin (2003), Social Networks and Organizations. Sage: London

Masum AA and Fatema-Tuz-Johora. 2012. Performance Evaluation of Selected Ceramic Companies of Bangladesh Asian Business Review, 1, 37-48.

Mehra, A., Kilduff, M., \& Brass, D. J. (2001). The social networks of high and low self-monitors: Implications for workplace performance. Administrative Science Quarterly, 46, 121-146.

Odumeru JA and Ilesanmi OA. 2013. The Effects of Human Resources Development on Financial Performance of Organisations Asian Business Review, 2, 19-23.

Oh, H., \& Kilduff, M. 2008. The ripple effect of personality on social structure: Self-monitoring origins of network brokerage. Journal of Applied Psychology, 93: 1155-1164.

Rosenberg, J. and Egbert, N. (2011), Online Impression Management: Personality Traits and Concerns for Secondary Goals as Predictors of Self-Presentation Tactics 
on Face book. Journal of Computer-Mediated Communication, 17: 1-18. Doi: 10.1111/j.10836101.2011.01560.x

Salia PJ and Mbwambo JS. 2014. Credit Characteristics and Business Performance: A Survey of Women owned Microenterprises in Tanzania Asian Business Review, 4, 12-18.
Snyder, M. (1974). Self-monitoring of expressive behavior. Journal of Personality and Social Psychology, 30, 526-537

Zaccaro, S. J., Foti, R. J., \& Kenny, D. A. (1991). Self-monitoring and trait-based variance in leadership: An investigation of leader flexibility across multiple group situations. Journal of Applied Psychology. 76, 308-315

\section{How to Cite}

Shaker F. 2014. The Social Network of High and Low Self- Monitors and its Impact on Organization's Performance Asian Business Review, 4, 100-104. 